\title{
Mixed epithelial and stromal tumor of the kidney: report of eight cases and literature review
}

\author{
Chao-jun Wang ${ }^{1 *}$, Yi-wei Lin ${ }^{1}$, Hua Xiang ${ }^{2}$, Dan-bo Fang ${ }^{1}$, Peng Jiang ${ }^{1}$ and Bo-hua Shen ${ }^{1}$
}

\begin{abstract}
Mixed epithelial and stromal tumor of the kidney (MESTK) is the term given to a class of uncommon biphasic tumors of the kidney, with few reported cases. We describe eight cases of MESTK with detailed clinicopathological data and follow-up information. With this report, we hope to increase clinical awareness that MESTK should be considered as one of the possible diagnoses for cystic renal mass, especially in peri-menopausal women or those who receive hormone therapy. In addition, regular follow-up is necessary for the any cases with malignant potential.
\end{abstract}

Keywords: Kidney, Mixed epithelial and stromal tumor

\section{Background}

Mixed epithelial and stromal tumor of the kidney (MESTK), is a rare kidney tumor [1]. The tumor was first identified by Michal and Syrucek in 1998 [2] and has been ariously termed 'cystic hamartoma of the renal pelvis,' 'adult mesoblastic nephroma,' 'cystic nephroma,' 'mature nephroblastic tumor' or 'cystic partially differentiated nephroblastoma.' To date, approximately 100 cases have been reported [3], with most of these reports focusing on the pathological and radiological features of the tumors. In this paper, we report detailed clinicopathological findings and clinical outcomes of a series of MESTK cases, and review the related literature.

\section{Case presentation}

During the period 2005 to 2012, eight cases with a diagnosis of MESTK were identified from the surgical pathology files of the urology department at our hospital. The clinical information and pathological data were obtained from the medical records, and demographic information, presenting symptoms, treatment, tumor size, immunohistochemical staining profiles, and scheduled follow-up data were collected.

The clinical features and follow-up data are summarized in Table 1. Of the eight patients, six were women and two were men. Mean age at presentation was 38 years. The

\footnotetext{
* Correspondence: wangchaojundf@hotmail.com

'Department of Urology, The First Affiliated Hospital, School of Medicine,

Zhejiang University, Qingchun Road 79, 310003 Hangzhou, Zhejiang

Province, China

Full list of author information is available at the end of the article
}

initial clinical presentation in one patient was flank pain, but all the other cases were discovered incidentally during regular examination. None of these patients had any history of hormonal therapy. In all cases, the computed tomography (CT) scan showed a partially cystic mass in the kidney, which was classified as a Bosniak III or IV lesion, indicating a pre-operative clinical impression of cystic renal cancer (Figure 1). Thus all eight patients underwent either nephrectomy or partial nephrectomy, and the diagnosis of MESTK was made postoperatively.

On gross examination, the excised specimens were found to be of varying size and consisted of multi-cystic and solid septa. Histological examination showed that all specimens were composed of cysts or dilated tubules of diverse diameter. All specimens presented with the characteristic mixture of epithelial and stromal components (Figure 2A). The tubular glandular epithelium was scattered within abundant spindle cells. Assays showed that the specimens had diverse immunochemical profiles (Table 1).

The patients were followed up for a mean duration of 28 months (4 to 50 months); at the end of which, all eight patients were alive without any evidence of recurrence or metastasis.

\section{Discussion}

MESTK, which was included in the WHO 2004 renal tumor classification, is a rare and distinctive kidney tumor composed of both epithelium and stroma with solid and cystic architecture [4]. As reported previously [5,6], MESTK occurs predominantly in middle-aged peri-menopausal 
Table 1 Clinicopathologic features of 8 patients with mixed epithelial and stromal tumor of the kidney

\begin{tabular}{|c|c|c|c|c|c|c|c|}
\hline $\begin{array}{l}\text { Patient } \\
\text { number }\end{array}$ & $\begin{array}{l}\text { Age, } \\
\text { years }\end{array}$ & Sex & $\begin{array}{l}\text { Clinical } \\
\text { presentation }\end{array}$ & Treatment & $\begin{array}{l}\text { Tumor } \\
\text { size, } \mathrm{cm}\end{array}$ & IHC profile & $\begin{array}{l}\text { Length of } \\
\text { follow-up, months }\end{array}$ \\
\hline 1 & 56 & $\mathrm{~F}$ & Incidental & Nephrectomy & 4.5 & Postive for ER and PR; negative for CD10 & 4 \\
\hline 2 & 60 & M & Incidental & Nephrectomy & 3.5 & Positive for CK, PR, SMA, desmin, and vimentin & 6 \\
\hline 3 & 40 & $\mathrm{~F}$ & Incidental & Nephrectomy & 4 & Positive for ER, PR, CK, vimentin, and CD10 & 19 \\
\hline 4 & 58 & M & Incidental & Nephrectomy & 4 & $\begin{array}{l}\text { Positive for CK, CD10, ER, PR, vimentin, and } \\
\text { desmin; negative for Melan-A and HMB-45 }\end{array}$ & 23 \\
\hline 5 & 54 & $\mathrm{~F}$ & Incidental & Partial Nephrectomy & 3.5 & Positive for ER and PR; negative for CD10 & 32 \\
\hline 6 & 47 & $\mathrm{~F}$ & Incidental & Partial Nephrectomy & 3.5 & $\begin{array}{l}\text { Positive for SMA, desmin, CD10, PR; } \\
\text { negative for HMB-45 }\end{array}$ & 42 \\
\hline 7 & 33 & $\mathrm{~F}$ & Pain & Nephrectomy & 9.5 & $\begin{array}{l}\text { Positive for desmin, CD99, and S-100; negative } \\
\text { for HMB-45, SMA, Myo-D1, CD31, and CD3 }\end{array}$ & 48 \\
\hline 8 & 51 & $\mathrm{~F}$ & Incidental & Nephrectomy & 7 & $\begin{array}{l}\text { Positive for ER, PR, desmin, and CD10; negative } \\
\text { for HMB-45 }\end{array}$ & 50 \\
\hline
\end{tabular}

Abbreviations: CK, cytokeratin; ER, estrogen receptor; IHC, Immunohistochemistry; PR, progesterone receptor; SMA, smooth muscle actin.

women and older women, especially those with a history of estrogen therapy, which indicates an underlying association between estrogen and MESTK. However, there are some rare male [5,7-9] or pediatric $[7,10,11]$ cases. In our series, most of the female patients were middleaged peri-menopausal to older women. This implies that a disturbed hormonal environment contributes to the pathogenesis of MESTK; however, we did not observe any correlation between estrogen therapy and MESTK, as all the patients denied histories of hormonal therapy. Thus, whether estrogen therapy is indeed associated with MESTK warrants further study.

The most common clinical presentations of MESTK include palpable abdominal mass, flank pain, and hematuria. However, in our series, almost all the cases were asymptomatic, and wee detected only incidentally during regular investigation. Radiologically, MESTK appears as well-circumscribed multi-septate cystic mass with solid components and thick or thin septa on both CT and magnetic resonance imaging scans, and thus can mimic complex renal cyst or cystic nephroma [12-14]. Lack of any typical radiological features makes it difficult to establish a precise diagnosis of MESTK preoperatively [3], thus, most cases are confirmed postoperatively, as in our series.

Histologically, MESTK is a dimorphic tumor composed of cysts and tubules embedded in the spindle cell stroma. The histogenesis of MESTK is unknown, and it has been proposed that both components of the tumor, stromal and epithelial, are neoplastic [15] and probably arise from a common cell of origin [16]. Miscroscopically, the stroma may resemble ovarian stroma, both morphologically and immunohistochemically (Figure 2B,C), and is composed of clusters of tubules or cystically dilated glands with variable lining [17]. Immunohistochemically, the epithelial components are usually positive for epithelial membrane antigen and cytokeratin. Spindle cells usually show diffusely and strongly positive immunostaining with desmin (Figure 2D), smooth muscle actin, and vimentin (Figure $2 \mathrm{E}$ ). In addition, there is a high frequency of estrogen and progesterone receptor present in the nuclei of the spindle cells (Figure 2F).
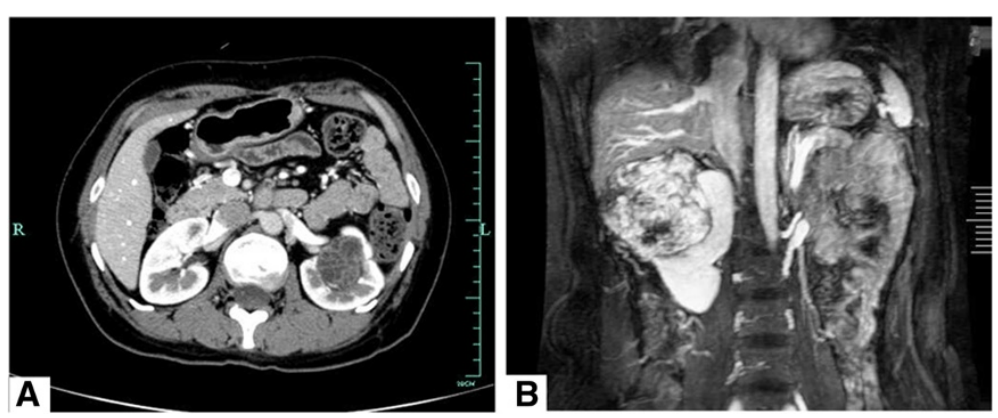

Figure 1 Representative radiological findings of mixed epithelial and stromal tumor of the kidney. (A) Patient 3. Abdominal computed tomography scan showed a left renal tumor with cystic and solid components. (B) Patient 7. T2-weighted coronal magnetic resonance imaging showed a giant, well-circumscribed, multi-cystic tumor that had originated from the right kidney. 


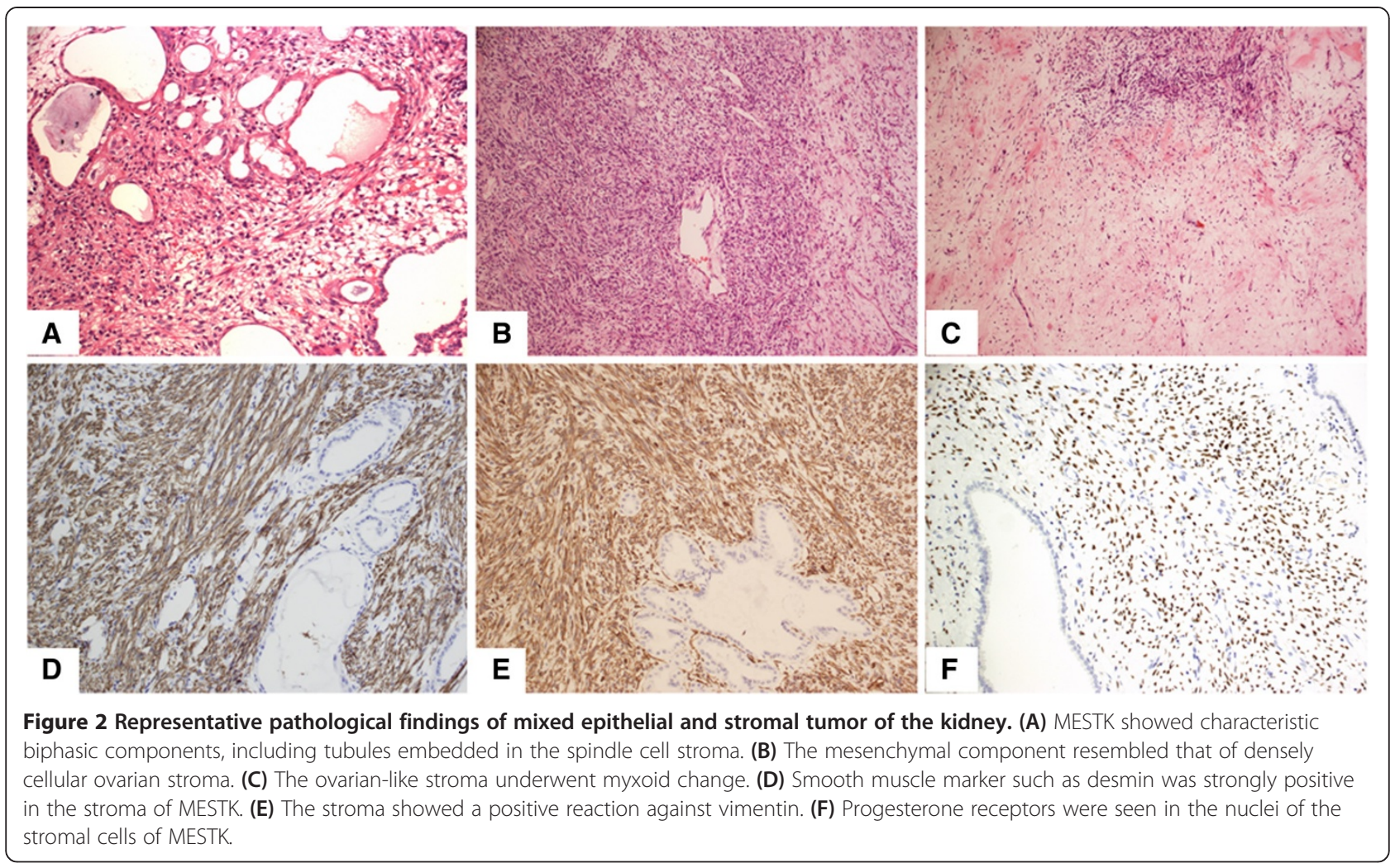

The distinctive ER and PR expression pattern seems to support the hypothesis that hormonal hyperstimulation contributes to tumorigenesis of MESTK.

MESTK used to be categorized as a benign renal tumor without recurrence or metastasis. However, malignant transformation of MESTK has been recently recognized, and a small number of aggressive cases with varied transformation have been described in the literature [8,9,18-21]. All of these malignant cases were female patients with the exception of one male patient reported by Suzuki et al. $[8,22]$. The prognosis for malignant MESTK varies from cases to cases, with half of the reported cases considered to have a dismal prognosis. There is no established predictor for prognosis, thus the histogenesis and clinical behavior of MESTK warrants further study.

\section{Conclusions}

MESTK is a rare clinical entity. It is generally considered to be a benign tumor with good prognosis, but there is malignant potential. MESTK should be considered as a possible diagnosis in cases of cystic renal mass, especially in peri-menopausal women or those who have received hormonal therapy.

\section{Consent}

Written informed consent was obtained from the patient for publication of this report and any accompanying images.

\section{Competing interests}

The authors declare that they have no competing interests.

\section{Authors' contributions}

CW and YL summarized the clinicopathologic data and writed the manuscript; HX provided the pathological information; DF and PJ collected the clinical data, and BS revised and edited the manuscript. All authors read and approved the final manuscript.

\section{Author details}

${ }^{1}$ Department of Urology, The First Affiliated Hospital, School of Medicine, Zhejiang University, Qingchun Road 79, 310003 Hangzhou, Zhejiang Province, China. 'Department of Pathology, The First Affiliated Hospital, School of Medicine, Zhejiang University, Hangzhou, Zhejiang Province, China.

Received: 10 February 2013 Accepted: 7 August 2013

Published: 20 August 2013

\section{References}

1. Kwon JE, Kang JH, Kwon GY: Mixed epithelial and stromal tumor of the kidney: a case report. J Korean Med Sci 2007, 22:159-162.

2. Michal M, Syrucek M: Benign mixed epithelial and stromal tumor of the kidney. Pathol Res Pract 1998, 194:445-448.

3. Moslemi MK: Mixed epithelial and stromal tumor of the kidney or adult mesoblastic nephroma: an update. Urol J 2010, 7:141-147.

4. Eble JN, Sauter G, Epstein JI, Sesterhenn IA: Pathology and Genetics of Tumours of the Urinary System and Male Genital Organs. Lyon: IARC Press; 2004.

5. Adsay NV, Eble JN, Srigley JR, Jones EC, Grignon DJ: Mixed epithelial and stromal tumor of the kidney. Am J Surg Pathol 2000, 24:958-970.

6. Michal M, Hes O, Bisceglia M, Simpson RH, Spagnolo DV, Parma A, Boudova L, Hora M, Zachoval R, Suster S: Mixed epithelial and stromal tumors of the kidney. A report of 22 cases. Virchows Arch 2004, 445:359-367.

7. Choy B, Gordetsky J, Varghese M, Lloyd GL, Wu G, Miyamoto H: Mixed epithelial and stromal tumor of the kidney in a 14 -year-old boy. Urol Int 2012, 88:247-248. 
8. Suzuki T, Hiragata S, Hosaka K, Oyama T, Kuroda N, Hes O, Michal M: Malignant mixed epithelial and stromal tumor of the kidney: Report of the first male case. Int $J$ Urol 2012, 20:448-450.

9. Menendez CL, Rodriguez VD, Fernandez-Pello S, Venta Menendez V, Poch Arenas M, Corrales B, Diaz Mendez B: A new case of malignant mixed epithelial and stromal tumor of the kidney with rhabdomyosarcomatous transformation. Anal Quant Cytol Histol 2012, 34:331-334.

10. Hara N, Kawaguchi M, Murayama S, Maruyama R, Tanikawa T, Takahashi K: Mixed epithelial and stromal tumor of the kidney in a 12-year-old girl. Pathol Int 2005, 55:670-676.

11. Vergine G, Drudi F, Spreafico F, Barbisan F, Brachi S, Collini P, Federici S, Pericoli R, Marsciani A, Vecchi V: Mixed epithelial and stromal tumor of kidney: an exceptional renal neoplasm in an 8-year-old prepubertal girl with isolated clitoral hypertrophy. Pediatr Hematol Oncol 2012, 29:89-91.

12. Wood CG 3rd, Casalino DD: Mixed epithelial and stromal tumor of the kidney. J Urol 2011, 186:677-678.

13. Chu LC, Hruban RH, Horton KM, Fishman EK: Mixed epithelial and stromal tumor of the kidney: radiologic-pathologic correlation. Radiographics 2010, 30:1541-1551.

14. Sahni VA, Mortele KJ, Glickman J, Silverman SG: Mixed epithelial and stromal tumour of the kidney: imaging features. BJU Int 2010, 105:932-939.

15. Montironi R, Mazzucchelli R, Lopez-Beltran A, Martignoni G, Cheng L, Montorsi F, Scarpelli M: Cystic nephroma and mixed epithelial and stromal tumour of the kidney: opposite ends of the spectrum of the same entity? Eur Urol 2008, 54:1237-1246.

16. Kum JB, Grignon DJ, Wang M, Zhou M, Montironi R, Shen SS, Zhang S, Lopez-Beltran A, Eble JN, Cheng L: Mixed epithelial and stromal tumors of the kidney: evidence for a single cell of origin with capacity for epithelial and stromal differentiation. Am J Surg Pathol 2011, 35:1114-1122.

17. Mohanty SK, Parwani AV: Mixed epithelial and stromal tumors of the kidney: an overview. Arch Pathol Lab Med 2009, 133:1483-1486.

18. Jung SJ, Shen SS, Tran T, Jun SY, Truong L, Ayala AG, Ro JY: Mixed epithelial and stromal tumor of kidney with malignant transformation: report of two cases and review of literature. Hum Pathol 2008, 39:463-468.

19. Svec A, Hes O, Michal M, Zachoval R: Malignant mixed epithelial and stromal tumor of the kidney. Virchows Arch 2001, 439:700-702.

20. Sukov WR, Cheville JC, Lager DJ, Lewin JR, Sebo TJ, Lewin M: Malignant mixed epithelial and stromal tumor of the kidney with rhabdoid features: report of a case including immunohistochemical, molecular genetic studies and comparison to morphologically similar renal tumors. Hum Pathol 2007, 38:1432-1437.

21. Nakagawa T, Kanai Y, Fujimoto H, Kitamura H, Furukawa H, Maeda S, Oyama T, Takesaki T, Hasegawa T: Malignant mixed epithelial and stromal tumours of the kidney: a report of the first two cases with a fatal clinical outcome. Histopathology 2004, 44:302-304.

22. Montironi R, Cheng L, Lopez-Beltran A, Scarpelli M: Editorial comment from Dr Montironi et al. to malignant mixed epithelial and stromal tumor of the kidney: report of the first male case. Int J Urol 2013, 20:451-452.

doi:10.1186/1477-7819-11-207

Cite this article as: Wang et al: Mixed epithelial and stromal tumor of the kidney: report of eight cases and literature review. World Journal of Surgical Oncology 2013 11:207.

\section{Submit your next manuscript to BioMed Central and take full advantage of:}

- Convenient online submission

- Thorough peer review

- No space constraints or color figure charges

- Immediate publication on acceptance

- Inclusion in PubMed, CAS, Scopus and Google Scholar

- Research which is freely available for redistribution

Submit your manuscript at www.biomedcentral.com/submit 